Correspondence

Anke Becker

Anke.Becker@genetik.

uni-bielefeld.de

Received 29 June 2004

Revised 5 October 2004

Accepted 7 October 2004

\section{Detailed studies of the binding mechanism of the Sinorhizobium meliloti transcriptional activator ExpG to DNA}

\author{
Birgit Baumgarth, ${ }^{1} \dagger$ Frank Wilco Bartels, ${ }^{2} \dagger$ Dario Anselmetti, ${ }^{2}$ \\ Anke Becker ${ }^{1}$ and Robert Ros ${ }^{2}$ \\ Lehrstuhl für Genetik, Fakultät für Biologie ${ }^{1}$ and Experimentelle Biophysik, Fakultät für Physik², \\ Universität Bielefeld, 33615 Bielefeld, Germany
}

\begin{abstract}
The exopolysaccharide galactoglucan promotes the establishment of symbiosis between the nitrogen-fixing Gram-negative soil bacterium Sinorhizobium meliloti 2011 and its host plant alfalfa. The transcriptional regulator ExpG activates expression of galactoglucan biosynthesis genes by direct binding to the $\exp A 1, \exp G / \exp D 1$ and $\exp E 1$ promoter regions. ExpG is a member of the MarR family of regulatory proteins. Analysis of target sequences of an ExpG(His) 6 fusion protein in the exp promoter regions resulted in the identification of a binding site composed of a conserved palindromic region and two associated sequence motifs. Association and dissociation kinetics of the specific binding of $\operatorname{Exp}(\mathrm{His})_{6}$ to this binding site were characterized by standard biochemical methods and by single-molecule spectroscopy based on the atomic force microscope (AFM). Dynamic force spectroscopy indicated a distinct difference in the kinetics between the wild-type binding sequence and two mutated binding sites, leading to a closer understanding of the ExpG-DNA interaction.
\end{abstract}

\section{INTRODUCTION}

The Gram-negative soil bacterium Sinorhizobium meliloti has the ability to fix molecular nitrogen in a symbiotic interaction with plants of the genera Medicago, Melilotus and Trigonella. The initiation of this symbiosis is a highly specific and complex developmental process, in which both partners undergo differentiation in a concerted way. In the early stages of this interaction, flavonoids in the root exudates induce the production of Nod factors by the bacteria which, in turn, trigger a developmental programme leading to the formation of root nodules (reviewed by Long, 2001; Spaink, 2000). The bacteria infect the nodule through infection threads and colonize the cytoplasm of plant cells. Once inside the plant cell, the bacteria differentiate into nitrogen-fixing bacteroids (reviewed by Oke \& Long, 1999).

Bacterial exopolysaccharides (EPSs) are important for nodule infection. S. meliloti is able to synthesize two acidic EPSs, succinoglycan (EPS I) and galactoglucan (EPS II). Infection of Medicago sativa root nodules by S. meliloti depends on low-molecular-mass forms of EPS I or EPS II (Glazebrook

Abbreviations: AFM, atomic force microscopy; EMSA, electrophoretic mobility shift assay; EPS, exopolysaccharide; EPS I, succinoglycan; EPS II, galactoglucan; $\mathrm{HTH}$, helix-turn-helix; $k_{\mathrm{on}}$, on-rate; $k_{\text {off, }}$ off-rate; $K_{\mathrm{d}}$ dissociation constant.

†B. B. and F.W.B. contributed equally to this work.
\& Walker, 1989; Gonzalez et al., 1996; Wang et al., 1999). EPS II is composed of alternating glucose and galactose residues which are decorated by acetyl and pyruvyl groups (Her et al., 1990). The biosynthesis of EPS II is directed by the $30 \mathrm{~kb}$ exp gene cluster, containing 22 genes organized in four operons (Becker et al., 1997; Rüberg et al., 1999).

Under standard culture conditions in a complex medium, wild-type strain S. meliloti 2011 synthesizes EPS I and only traces of EPS II. The biosynthesis of EPS II is increased by phosphate-limiting conditions (Zhan et al., 1991) or a mutation in either of the regulatory genes mucR (Keller et al., 1995; Zhan et al., 1989) and $\exp R$ (Glazebrook \& Walker, 1989; Pellock et al., 2002), which are unlinked to the $\exp$ gene cluster. Extra copies of the regulatory gene $\exp G$ located in the exp gene cluster (Astete \& Leigh, 1996; Becker et al., 1997; Rüberg et al., 1999) stimulate transcription of the $\exp A, \exp D$ and $\exp E$ operons (Rüberg et al., 1999). Under phosphate-limiting conditions the enhanced transcription of these operons requires $\exp G$, implying that ExpG acts as a transcriptional activator of exp gene expression (Astete \& Leigh, 1996; Rüberg et al., 1999).

ExpG was grouped into the MarR family of regulatory proteins (Becker et al., 1997). Like many other transcriptional regulators MarR-type regulators bind DNA through a helix-turn-helix (HTH) motif (Cohen et al., 1993; Sulavik et al., 1995). An assortment of biological functions, e.g. the expression of resistance to multiple antibiotics, detergents 
and oxidative stress agents, organic solvents and pathogenic factors, is controlled by members of the MarR family (Alekshun \& Levy, 1999; Miller \& Sulavik, 1996). Most members act as repressors and only a few as activators (Egland \& Harwood, 1999; Komeda et al., 1996; Oscarsson et al., 1996). Recently, we showed that ExpG itself exerts positive regulation of exp gene expression by binding to the $\exp A 1, \exp G / \exp D 1$ and $\exp E 1$ promoter regions in the exp gene cluster (Bartels et al., 2003).

In this paper we describe three distinct DNA sequence elements of the ExpG binding sites and their contribution to the specific binding process. Association and dissociation kinetics were characterized by ensemble and singlemolecule methods.

\section{METHODS}

Bacterial strains, plasmids and growth conditions. Escherichia coli SURE (Young \& Davis, 1983), used as expression strain, was cultivated in SB (Super broth) medium (32 g tryptone $1^{-1}, 20 \mathrm{~g}$ yeast extract $1^{-1}$ and $5 \mathrm{~g} \mathrm{NaCl} \mathrm{l}^{-1}$, adjusted to $\mathrm{pH} \mathrm{7 \cdot 6)}$ at $37^{\circ} \mathrm{C}$. Plasmid pHisGC31 was constructed by insertion of a 589 bp EcoRIEcl136II fragment carrying expG of S. meliloti 2011 (Casse et al., 1979) into vector pEXP2 (MBBL, Bielefeld, Germany). This fragment was amplified by PCR using the primers expG.EXP2.5 (5'-AAAAGAATTCAAACCACAGGATACTCTATCCG) and HisG.EXP2.3 (5' AAAAGAGCTCTCAgtgatggtgatggtgatgGATGCCGTAGCGTGCGGC) (EcoRI and Ecl136II restriction sites are underlined, the antisense sequence of the stop codon is printed in bold face and antisense His codons are in lower case) and pARIIa as template (Becker et al., 1997). Expression of the hybrid gene resulted in a fusion protein consisting of ExpG from Asn-2 to Ile-190, with a (His) 6 C-terminal tag and ten additional N-terminal amino acids (MAIFEMLRNS).

Proteins. Expression, of recombinant ExpG(His) ${ }_{6}$ fusion protein was performed essentially as described previously (Bartels et al., 2003). Purification was carried out by Ni-NTA affinity chromatography (Qiagen). Purified fusion protein was concentrated using an Ultrafree 4 centrifugal concentrator (Millipore), resuspended in buffer $(250 \mathrm{mM} \mathrm{NaCl}, 10 \mathrm{mM}$ Tris, $1 \mathrm{mM} \mathrm{DTT}$ and $50 \%$, v/v, glycerol) and stored at $-20{ }^{\circ} \mathrm{C}$. The concentration of purified protein was determined by using the Bio-Rad Protein Assay (Bradford, 1976).

DNA fragments. DNA fragments I, II and III (see Fig. 2a) and competitor fragments for electrophoretic mobility shift assays (EMSAs) were generated by PCR as described previously (Bartels et al., 2003). Following hybridization of the oligonucleotides (Fig. 2b) and their respective antisense oligonucleotides (synthesized by Qiagen) as described by Bertram-Drogatz et al. (1998), the double-stranded hybridization products were inserted into pUC18 (Yanisch-Perron et al., 1985). The resulting plasmids were used as templates for amplification of fragments KF-Alc, d, e, f, g and h, KF-Ge and KFE1e by PCR (for fragment lengths, see Fig. $2 \mathrm{~b}$ ) employing primers M13uni (5'-CGCCAGGGTTTTCCCAGTCACGAC-3') and M13rev (5'-AGCGGATAACAATTTCACACAGGA-3'). These plasmids were also used for amplification of DNA fragments KF-Ale, $f, g$ and $h$ for atomic force microscopy (AFM) force spectroscopy employing primers M13uni (see above) and 5'SH-labelled primer M13rev (see above). DNA fragments for AFM imaging were amplified by PCR with primer ExpG1 (5'-AAAACTCGAGAGTCGTGTCTTACCGGGTTG-3') and M13uni (see above) from pFPG3/41 (pUC18 carrying the 348 bp EcoRI-HindIII fragment that comprises the intergenic region between $\exp D 1$ and $\exp G$ ).
EMSA analysis. Cy3-labelled DNA fragments I, II and III (see Fig. 1a) in various concentrations were mixed with purified ExpG(His) ${ }_{6}\left(0.013 \mu \mathrm{g}^{-1}\right)$ in a reaction buffer containing $50 \mathrm{mM}$ Tris/HCl, pH 8.0, $100 \mathrm{mM} \mathrm{NaCl}, 0.1 \mathrm{mM} \mathrm{MgSO}_{4}, 5 \%$ glycerol, $0.05 \mathrm{mg}$ sonicated herring testis DNA ml $\mathrm{m}^{-1}$ and $0.5 \mathrm{mg}$ bovine serum albumin $\mathrm{ml}^{-1}$ and were subjected to EMSAs (Bartels et al., 2003). In competition assays, protein was added to Cy3-labelled DNA fragments in the presence of various concentrations of competitor DNA fragments. After incubation at $20^{\circ} \mathrm{C}$ for $15 \mathrm{~min}$, the reaction was loaded onto a $2 \%$ non-denaturing agarose gel prepared in gel buffer $(40 \mathrm{mM}$ Tris base, $10 \mathrm{mM}$ sodium acetate and $1 \mathrm{mM}$ EDTA adjusted to $\mathrm{pH} 7 \cdot 8$ with acetic acid) and electrophoresed at $4{ }^{\circ} \mathrm{C}$ in gel buffer at $4.5 \mathrm{~V} \mathrm{~cm}^{-1}$ for $2 \mathrm{~h}$. Gel images were acquired using a Typhoon 8600 Variable Mode Imager (Amersham Bioscience).

Determination of on- and off-rates. Association kinetics for the binding reactions of ExpG(His) ${ }_{6}$ to fragments I, II and III (Fig. 2a) were followed by loading samples taken after various time intervals between 0 and 15 min from a standard assay on an already electrophoresing agarose gel (Fried \& Crothers, 1981; Lane et al., 1992). For determination of the on-rate $\left(k_{\mathrm{on}}\right)$ of the reaction, initial rate data were evaluated by calculating $k_{\text {on }}=\mathrm{d}[1 /(P-N)] \ln [N(P-P N) /$ $P(N-P N)] / \mathrm{d} t$ (Lane et al., 1992), where $P$ is the concentration of free protein, $P N$ the concentration of the protein-DNA complex, $N$ the concentration of free DNA substrate, and $t$ the time of sampling. The kinetics of dissociation of $\operatorname{ExpG(His)})_{6}$ from fragments I, II and III (Fig. 2a) were investigated by adding a 50-fold excess of unlabelled competitor fragment to a mixture containing proteinDNA complexes and determining the degree of competition after various time intervals, as described above. The off-rate $\left(k_{\text {off }}\right)$ was determined by calculating $k_{\mathrm{off}}=-\mathrm{d}\left[\ln \left(P N / P N_{0}\right)\right] / \mathrm{d} t$ (Lane et al., 1992), where $P N$ is the concentration of the protein-DNA complex at sampling point after the addition of competitor, $P N_{0}$ represents the concentration of the protein-DNA complex directly before the addition of competitor, and $t$ is the time of sampling. The dissociation constant $\left(K_{\mathrm{d}}\right)$ of the protein-DNA complex was calculated as the ratio of the off-rate $\left(k_{\text {off }}\right)$ over the on-rate $\left(k_{\text {on }}\right)$ (Bisswanger, 1994; Lane et al., 1992). Experiments to determine the on- and offrates were repeated three times.

HPLC gel-permeation chromatography of ExpG(His) 6. Size dis-

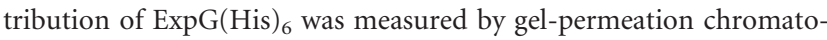
graphy on a TSK Gel G2000SW column (TosoHaas) with a flow rate of $0.5 \mathrm{ml} \mathrm{min}{ }^{-1}$ (eluent: $50 \mathrm{mM}$ sodium phosphate buffer, $\mathrm{pH} 7 \cdot 0$ ). Calibration was performed with an LMW Gel Filtration Calibration Kit (Amersham Biosciences). Protein absorbance was measured at $280 \mathrm{~nm}$.

AFM imaging. DNA fragments for AFM imaging consisted of $158 \mathrm{bp}$ of the $\exp G$ promoter region and a non-binding sequence of $990 \mathrm{bp}$. DNA $\left(0 \cdot 2 \mathrm{ng} \mathrm{\mu l}^{-1}\right)$ and $\operatorname{ExpG}$ protein $\left(0 \cdot 2 \mathrm{ng} \mathrm{\mu l}^{-1}\right)$ were mixed in buffer solution ( $50 \mathrm{mM}$ Tris, $25 \mathrm{mM} \mathrm{NaCl}, 4 \mathrm{mM} \mathrm{NiCl}{ }_{2}$, $\mathrm{pH} 8 \cdot 3$ ) and left to incubate for $5 \mathrm{~min}$ before being brought to a freshly cleaved mica surface (Provac AG, Balzers, Liechtenstein) which was then immediately installed under the AFM liquid cell. The concentration of $\mathrm{Ni}^{2+}$ counter-ions was optimized to yield a flexible immobilization of the DNA to the mica surface by electrostatic attraction (Hansma \& Laney, 1996). Protein-DNA complexes were investigated at $25^{\circ} \mathrm{C}$ with a commercial AFM (Multimode, Veeco Instruments) in tapping mode, using oxide-sharpened $\mathrm{Si}_{3} \mathrm{~N}_{4}$ cantilevers (Veeco Instruments) at a resonance frequency of about $28 \mathrm{kHz}$. Images were taken at a scan rate of $2 \mathrm{~Hz}$, while the setpoint was kept at $0.2 \mathrm{~V}$. Amplitude and phase were recorded simultaneously (from the signal in trace/retrace direction) to distinguish between DNA and protein (Lysetska et al., 2002).

Sample surface and AFM tip modification. For force spectroscopy measurements, sample surfaces and AFM tips were 
functionalized as described previously (Bartels et al., 2003). Briefly, $\mathrm{Si}_{3} \mathrm{~N}_{4}$ cantilevers (Microlever; Thermomicroscopes, Sunnyvale, CA, USA) were first activated by dipping for $10 \mathrm{~s}$ in concentrated nitric acid and silanized in a solution of $2 \%$ aminopropyltriethoxysilane (Sigma) in dry toluene for $2 \mathrm{~h}$. After washing with toluene, the cantilevers were incubated with $1 \mathrm{mM} N$-hydroxysuccinimide-poly (ethylene glycol)-maleimide (Shearwater Polymers) in $0 \cdot 1 \mathrm{M}$ potassium phosphate buffer, $\mathrm{pH} 8 \cdot 0$, for $30 \mathrm{~min}$ at room temperature. After washing with phosphate buffer, the cantilevers were incubated overnight at $4{ }^{\circ} \mathrm{C}$ with $10 \mathrm{ng} \mu \mathrm{l}^{-1}$ of the respective DNA target sequence (see above) bearing a thiol label in binding buffer solution (50 mM Tris/ $\mathrm{HCl}, 100 \mathrm{mM} \mathrm{NaCl}, 0 \cdot 1 \mathrm{mM} \mathrm{NiCl}_{2}, \mathrm{pH} 8 \cdot 3$ ). The cantilevers were washed with binding buffer and used for force spectroscopy experiments. Modified tips were usable for at least a week if stored at $4{ }^{\circ} \mathrm{C}$.

Mica surfaces (Provac) were silanized with aminopropyltriethoxysilane in an exsiccator (Lyubchenko et al., 1993) and incubated with $4 \mu \mathrm{M}$ ExpG(His) ${ }_{6}$ protein and $20 \mu \mathrm{M}$ bis(sulfosuccinimidyl)suberate sodium salt (Sigma) in $0 \cdot 1 \mathrm{M}$ potassium phosphate buffer, $\mathrm{pH} 7 \cdot 5$, for $1 \mathrm{~h}$ at $4{ }^{\circ} \mathrm{C}$. The sample was washed with binding buffer afterwards. Modified surfaces were stable for at least 2 days if stored at $4{ }^{\circ} \mathrm{C}$.

Dynamic force spectroscopy. Force spectroscopy measurements were performed with a commercial AFM head (Multimode; Veeco Instruments) at $25^{\circ} \mathrm{C}$. Acquisition of the cantilever deflection force signal and the vertical movement of the piezoelectric elements was controlled by a 16 bit AD/DA card (PCI-6052E; National Instruments) and a high-voltage amplifier $(600 \mathrm{H}$; NanoTechTools) via a home-built software based on Labview (National Instruments). The deflection signal was low-pass filtered $(<6 \mathrm{kHz})$ and box-averaged by a factor of 10 , giving a typical experimental dataset of 2000 points per force-distance curve.

The spring constants of all AFM cantilevers were calibrated by the thermal fluctuation method (Hutter \& Bechhoefer, 1993) with an absolute uncertainty of approximately $15 \%$. Spring constants of the cantilevers used ranged from $12 \mathrm{pN} \mathrm{nm}^{-1}$ to $15 \mathrm{pN} \mathrm{nm}^{-1}$.

For loading-rate-dependent measurements, the retract velocity of the piezo was varied while keeping the approach velocity constant. The measured force-distance curves were analysed with a Matlab program (MathWorks) and corrected to display the actual molecular distances calculated from the $z$ piezo extension. To obtain the loading rate, the retract velocity was then multiplied by the elasticity of the molecular system, which was determined from the slope of the corrected forcedistance curves on the last 20 data points before the unbinding events.

\section{RESULTS AND DISCUSSION}

\section{A palindromic sequence in the exp promoter regions is required for binding of the ExpG protein}

Recently, we demonstrated the binding of ExpG to promoter regions in the exp gene cluster (Bartels et al., 2003). To localize the DNA region recognized by ExpG more precisely, we tested the specificity of DNA binding by ExpG in competition experiments. For this purpose, an ExpG(His $)_{6}$ fusion protein was expressed and purified by Ni-NTA affinity chromatography. In SDS-PAGE the purified protein exhibited a major band migrating at approximately $23 \mathrm{kDa}$ which was detected using an antiHis-tag antibody (data not shown). This corresponds well with the calculated molecular mass of $23 \cdot 2 \mathrm{kDa}$. An apparent molecular mass of the $\operatorname{ExpG}(\mathrm{His})_{6}$ protein of $44 \cdot 4 \mathrm{kDa}$ in a $50 \mathrm{mM}$ sodium phosphate buffer $(\mathrm{pH} 7 \cdot 0$ ) in non-denaturing conditions was determined by gel permeation chromatography (data not shown). This major peak probably represented a dimer. In addition to this peak, three higher molecular mass forms that may include a tetramer were detected in lower concentrations. This leads to the speculation that ExpG forms dimers and binds to its target DNA at least as a dimer.

The topography of the binding site was investigated by AFM in buffer solution. The $158 \mathrm{bp}$ promoter region of $\exp G$ (Bartels et al., 2003) was extended by a 990 bp nonbinding sequence at one end, resulting in a $390 \mathrm{~nm}$ DNA fragment suitable for AFM imaging. In accordance with this experimental setup, bound proteins were observed at only one end of a given DNA fragment, confirming the binding to the promoter region. Furthermore, AFM revealed a change in DNA conformation during the process of unbinding (Fig. 1), with a different curvature of the promoter region. Such a structural change was a recurring motif and has been observed for at least eight different DNA fragment-protein complexes. Proteins binding at other DNA sites or without structural transition have not been observed. Although the unbound and bound state was not directly observed in reverse order, it can be assumed that the DNA acquires its characteristic bend during the formation of the protein-DNA complex.

A conserved $21 \mathrm{bp}$ region with a palindromic sequence which may constitute the binding site of ExpG was recently found in the promoter regions of $\exp A 1, \exp G$, $\operatorname{expD1}$ and $\operatorname{expE1}$ (Bartels et al., 2003; Lloret et al., 2002). In addition to this conserved sequence two further regions in the exp promoter fragments, box 1 and box 2, share similarities (Fig. 2b). Eight different competitor fragments (Fig. 2b) were designed to test the importance of these two boxes and the palindromic sequence for binding of ExpG(His) ${ }_{6}$. The double-stranded hybridization products from $28 \mathrm{bp}$ to $80 \mathrm{bp}$ (see Methods and Fig. 2b) were not effective competitors in EMSA experiments. To exclude the possibility that the competitor fragments were too short for protein binding, although they may carry the specific binding-site sequence, these fragments were cloned into the pUC18 vector. Flanking sequences derived from the pUC18 vector added $102 \mathrm{bp}$ to the specific sequences from the exp promoter regions so that the fragments measured from $130 \mathrm{bp}$ to $182 \mathrm{bp}$ (Fig. 2b).

Competitor fragments KF-Ale, g and h, KF-Ge and KF-E1e contained the three motifs of the $\exp A, \exp G / \exp D$ and $\exp E$ promoter regions, respectively. Fragments KF-Ale (Fig. 3a), KF-Ge (Fig. 3b) and KF-Ele (Fig. 3c) with the wild-type sequence were effective competitors for the binding of ExpG(His) 6 to DNA fragments I, II and III containing the $\exp A, \exp G / \exp D$ and $\exp E$ promoter regions, respectively. KF-A1d, containing only the conserved palindrome region (Fig. 2b) did not compete out binding of ExpG(His) 6 (Fig. 3a). This was also the case for fragment KF-A1c, which 

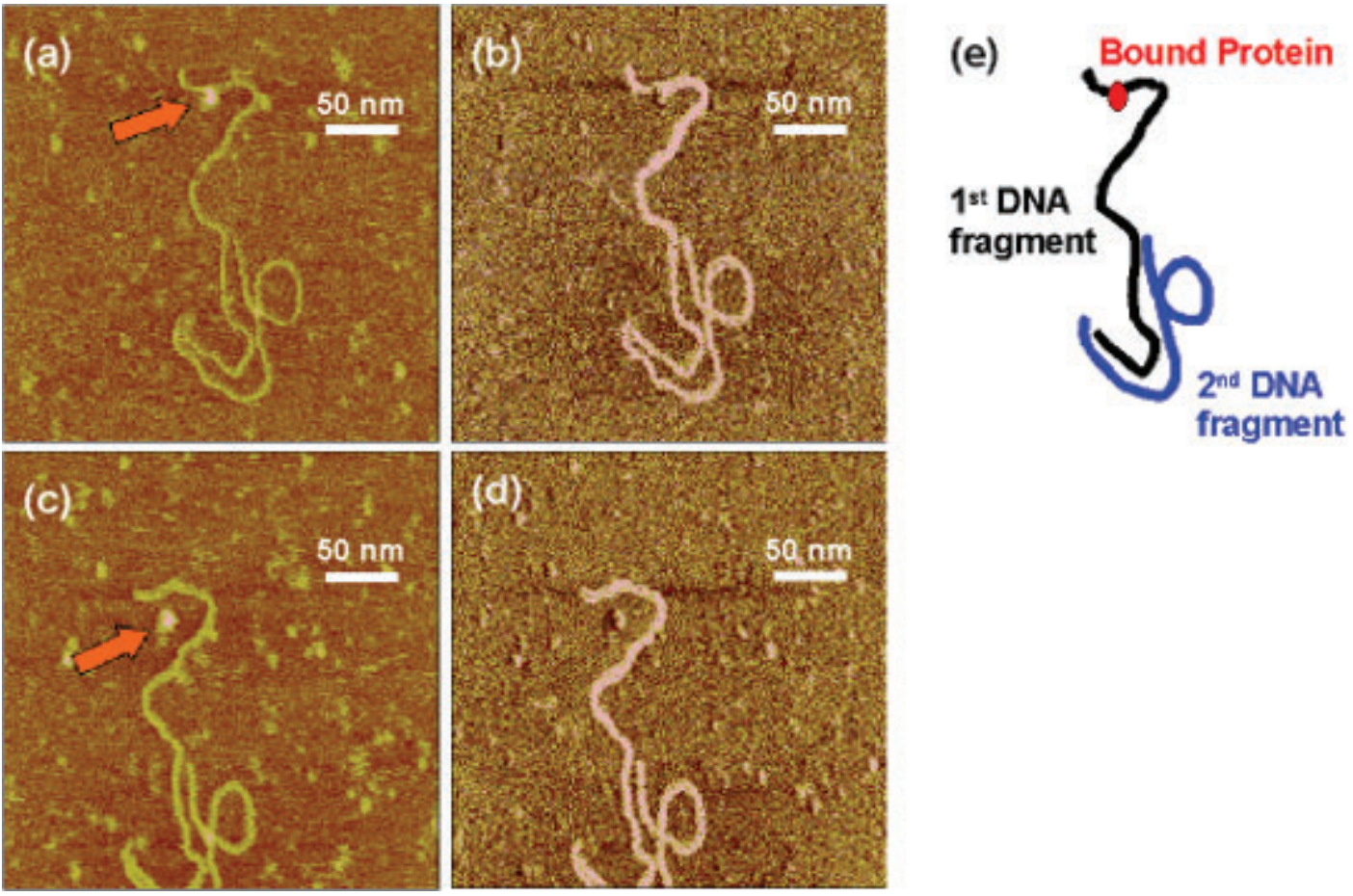

Fig. 1. AFM reveals a change in DNA conformation during unbinding of the protein-DNA complex. DNA fragments $390 \mathrm{~nm}$ long, containing the expG promoter region at one end, were imaged in buffer solution ( $50 \mathrm{mM} \mathrm{Tris,} 25 \mathrm{mM} \mathrm{NaCl}, 4 \mathrm{mM} \mathrm{NiCl} 2$, $\mathrm{pH} 8.3$ ) in the presence of $\operatorname{Exp}(\mathrm{His})_{6}$ proteins. Images on the left show the topography ( $z$ range $3.5 \mathrm{~nm}$ ), while the corresponding phase information $\left(z\right.$ range $8.0^{\circ}$ ) is presented on the right. Height and phase signal were recorded simultaneously to distinguish between protein and DNA. The protein exhibits a negative phase shift (i.e. appears darker in the phase image) while the DNA shows a positive phase shift (i.e. appears brighter) (Lysetska et al., 2002). Images (a) and (b) show two DNA fragments (probably stabilizing each other by the medium of counter-ions), one of which carries a bound protein. When the protein (red arrow) breaks away (time between images: 9 min), the curvature of the DNA binding region changes ( $c$ and $d)$. The bound state and the position of the two DNA fragments are shown in cartoon form in (e).

(a)
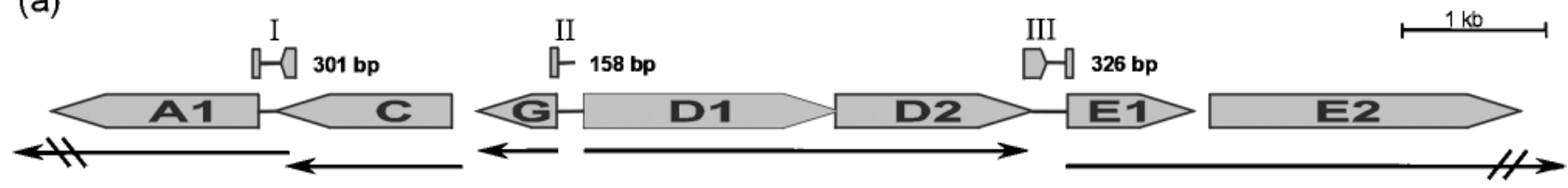

(b)

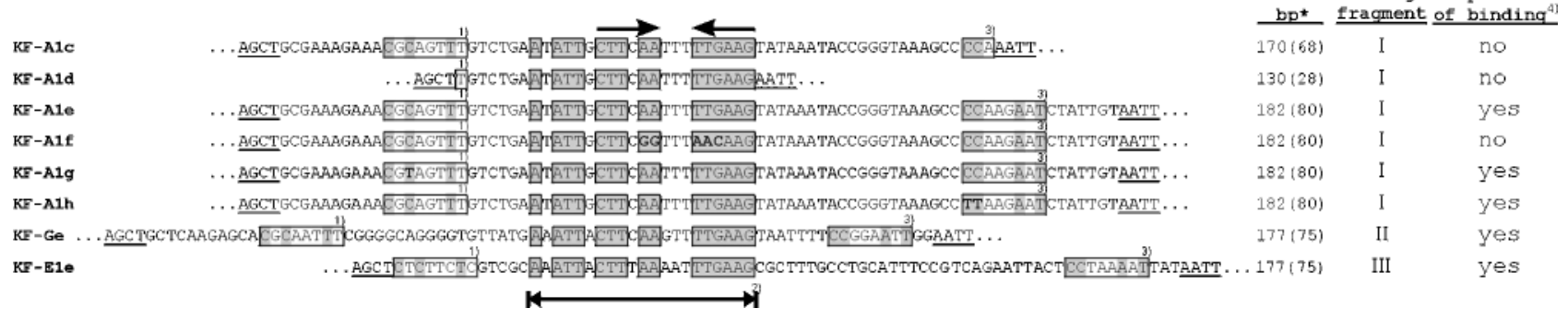

Fig. 2. (a) The exp gene region from expA1 to expE2 (10330 nt) of the exp gene cluster of S. meliloti 2011 (Casse et al., 1979). Transcriptional units are marked by arrows. I, II and III are DNA fragments for EMSAs. (b) Alignment of the competitor fragments. Residues identical in the $\exp A 1, \exp G$ and $\exp E 1$ promoter regions are boxed and shaded. ${ }^{1)}$ Box $1,{ }^{2)}$ conserved region, ${ }^{3)}$ box 2 . Mutations in box 1 , the conserved palindrome region and box 2 are in bold. Inverted arrows indicate a palindrome found within the conserved region. AGCT, Hindlll overhang; AATT, EcoRI overhang. *Fragment length after amplification by PCR; length of the native S. meliloti sequence is given in parentheses. ${ }^{4)}$ See Fig. 3. 
(a)

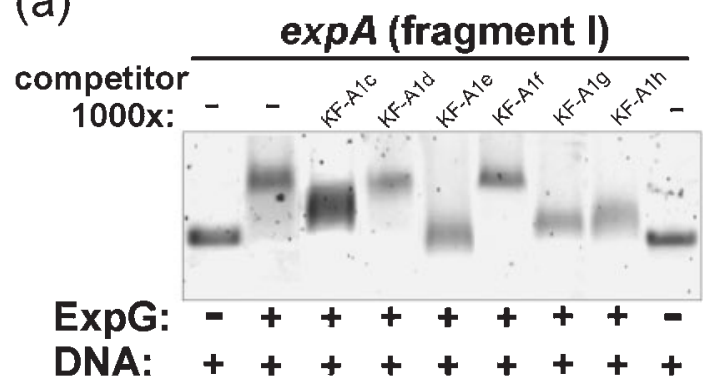

(b)

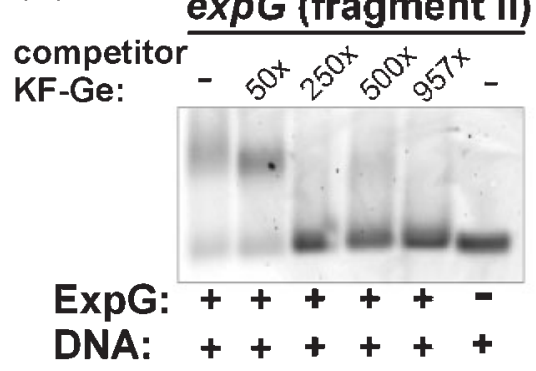

(c)

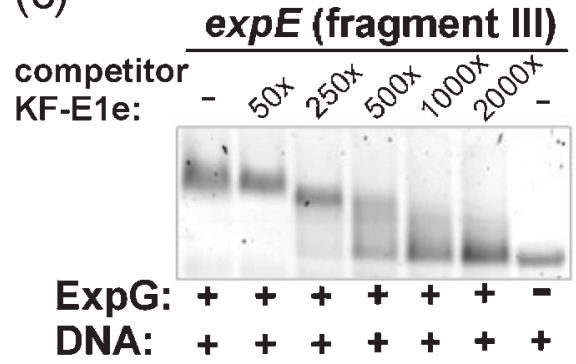

Fig. 3. EMSAs with purified $\operatorname{ExpG}(\mathrm{His})_{6}$ fusion protein, (a) DNA fragment I, (b) DNA fragment II, (c) DNA fragment III (see Fig. 2a) and specific competitor DNA fragments (see Fig. 2b). Protein was added to all reactions to give a final protein concentration of $0.013 \mu \mathrm{g}^{-1}$. Unlabelled competitor DNA was added in increasing amounts from 50-fold to 2000-fold excess over the Cy3-labelled DNA fragments.

included box 1, the palindrome region and 3 bp of box 2 (Figs $2 \mathrm{~b}$ and $3 \mathrm{a}$ ), suggesting that at least the palindrome region and box 2 are required for binding of ExpG.

Exchange of five nucleotides in the palindrome of the KFAle fragment resulted in fragment KF-Alf (Fig. 2b), which

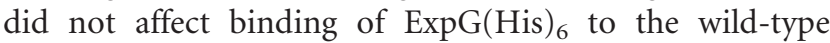
sequence in the competition experiments (Fig. 3a). This indicates that the conserved palindromic sequence is essential for binding of $\operatorname{ExpG}(\mathrm{His})_{6}$. Neither a mutation in box 1, KF-A1g (Fig. 2b), nor a mutation in box 2, KFAlh (Fig. 2b), completely blocked binding of $\operatorname{ExpG(His)_{6}}$ in the competition experiment (Fig. 3a). However, competition with fragments $\mathrm{KF}-\mathrm{A} 1 \mathrm{c}, \mathrm{g}$ and $\mathrm{h}$ resulted in an incomplete shift (Fig. 3a), indicating a lower binding

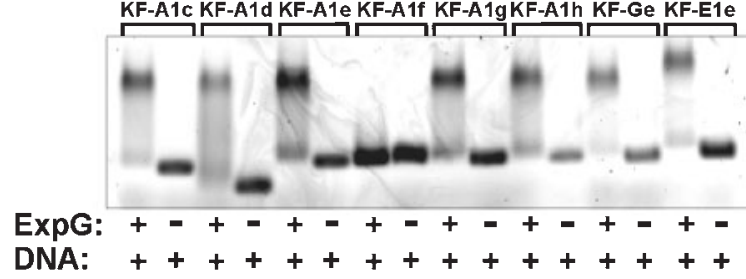

Fig. 4. EMSA with purified $\operatorname{Exp} \mathrm{G}(\mathrm{His})_{6}$ fusion protein and Cy3labelled DNA fragments, which were further used as specific unlabelled competitor DNA (Figs $2 b$ and 3a). Protein was added to all reactions to give a final protein concentration of $0.02 \mu \mathrm{g}^{-1}$. DNA was added to give a final concentration ranging from $0.05 \mathrm{ng}^{-1} \mathrm{l}^{-1}$ to $0.25 \mathrm{ng} \mu \mathrm{l}^{-1}$.

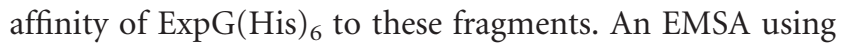
the eight specific competitor fragments as Cy3-labelled DNA fragments confirmed that the palindrome is essential for binding of $\operatorname{ExpG}(\mathrm{His})_{6}$. ExpG(His) 6 completely reduced the electrophoretic mobility of each fragment except for the KF-Alf fragment, which contains the mutated palindrome (Fig. 4). Nevertheless, the failure of the fragments containing only the palindrome region (KF-Ald) or the palindrome region and box 1 (KF-A1c) in competition showed that the additional motifs box 1 and box 2 influence binding of $\operatorname{ExpG}(\mathrm{His})_{6}$ as well. Possibly the change of 1 or $2 \mathrm{bp}$ in box 1 and box 2 was not sufficient to destroy the function of these motifs.

The above results were confirmed by AFM force spectroscopy experiments. In this direct approach, binding of the ExpG(His) ${ }_{6}$ protein to different DNA fragments can be observed on a single-molecule basis (Bartels et al., 2003). By covalently attaching the binding partners to the AFM tip and the sample surface, respectively, unbinding forces of the protein-DNA complex can be measured during multiple approach-retract cycles of tip and surface. The unbinding forces under a single retract velocity show a nearly Gaussian distribution around the most probable unbinding force (Fig. 5). Again, mutations in the palindrome (fragment KF-Alf) led to no recognizable binding (Fig. 5b), whereas the fragments with mutations in box 1 (KF-A1g) or box 2 (KF-Alh) reached almost the same binding probability as the wild-type fragment (KF-Ale).

The function and structure of DNA-binding transcription factors of the MarR family are well investigated but little is known about their binding sites. We were able to narrow down the region required for binding of $\operatorname{ExpG}(\mathrm{His})_{6}$ to a $63 \mathrm{bp}$ region for the expA1 promoter, a $62 \mathrm{bp}$ region for the $\exp G$ promoter, and a 72 bp region for the $\exp E 1$ promoter. We suggest that the 21 bp conserved sequence within the different exp promoter regions is the core region required for the binding of an ExpG dimer and the additional motifs box 1 and/or box 2 enable the complete DNA-protein interaction. A similar situation was suggested for LysR-type regulators (LTTR). A typical LTTR 


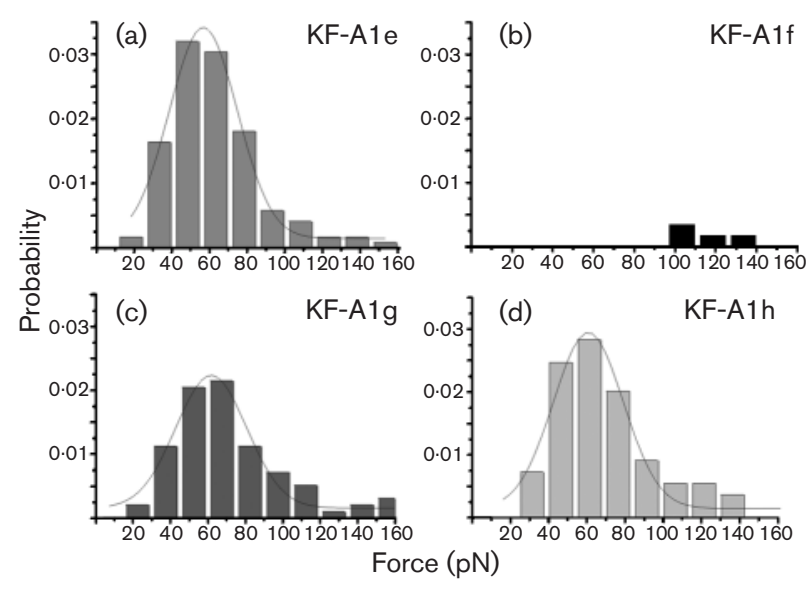

Fig. 5. Single-molecule force spectroscopy. Unbinding of the protein-DNA complex was measured in buffer solution $(50 \mathrm{mM}$ Tris/ $\mathrm{HCl}, 100 \mathrm{mM} \mathrm{NaCl}, 0.1 \mathrm{mM} \mathrm{NiCl} 2, \mathrm{pH}$ 8.3) for the ExpG protein and different DNA fragments: the wild-type sequence (KF-A1e) and fragments with mutations in the palindrome (KF$\mathrm{A} 1 \mathrm{f})$, box 1 (KF-A1g) or box 2 (KF-A1h). Evidently, the palindrome was necessary for binding (b), while mutations in the box 1 and box 2 regions only slightly reduced the probability of binding $(c-d)$ with respect to the wild-type sequence (a).

binds to a sequence of approximately $50-60 \mathrm{bp}$, which contains two distinct sites, a recoginition-binding site (RBS) recognized primarily by the LTTR, and an activationbinding site (ABS) (Schell, 1993). The long DNA sequence stretch containing the RBS and ABS and the size range of active LTTRs suggest that in vivo these regulators are multimeric and bind probably as dimers or tetramers (Henikoff et al., 1988).

ExpG, which contains a HTH-MarR motif at the Cterminus (residues 70-164), is a member of the MarR

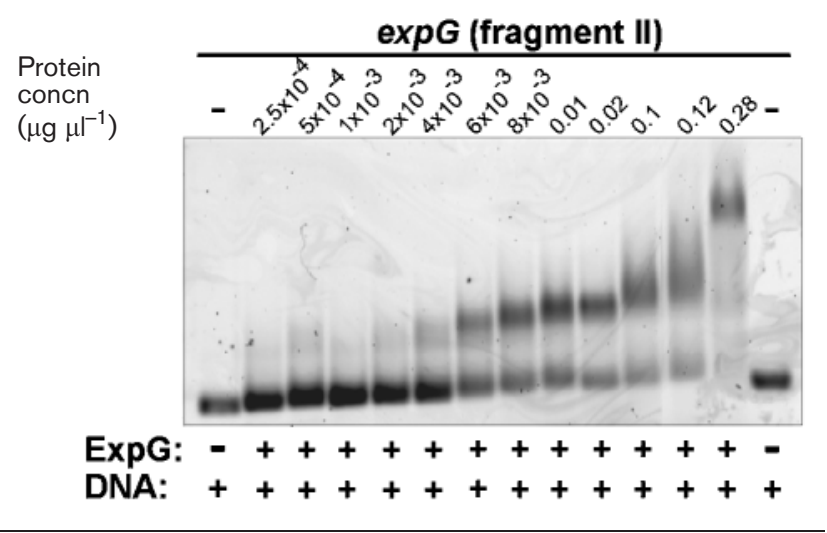

Fig. 6. EMSA with purified $\operatorname{Exp}(\mathrm{His})_{6}$ fusion protein of increasing concentration and DNA fragment II (see Fig. 2a). DNA was added to all reactions to give a final DNA concentration of $3 \cdot 7 \mathrm{ng} \mu \mathrm{l}^{-1}$. family, which belongs to a supergroup of eight regulator families sharing a conserved extended sequence including the classical HTH motif (Perez-Rueda \& Collado-Vides, 2001). The HTH motif is one of the most common DNAbinding motifs in proteins that control transcription
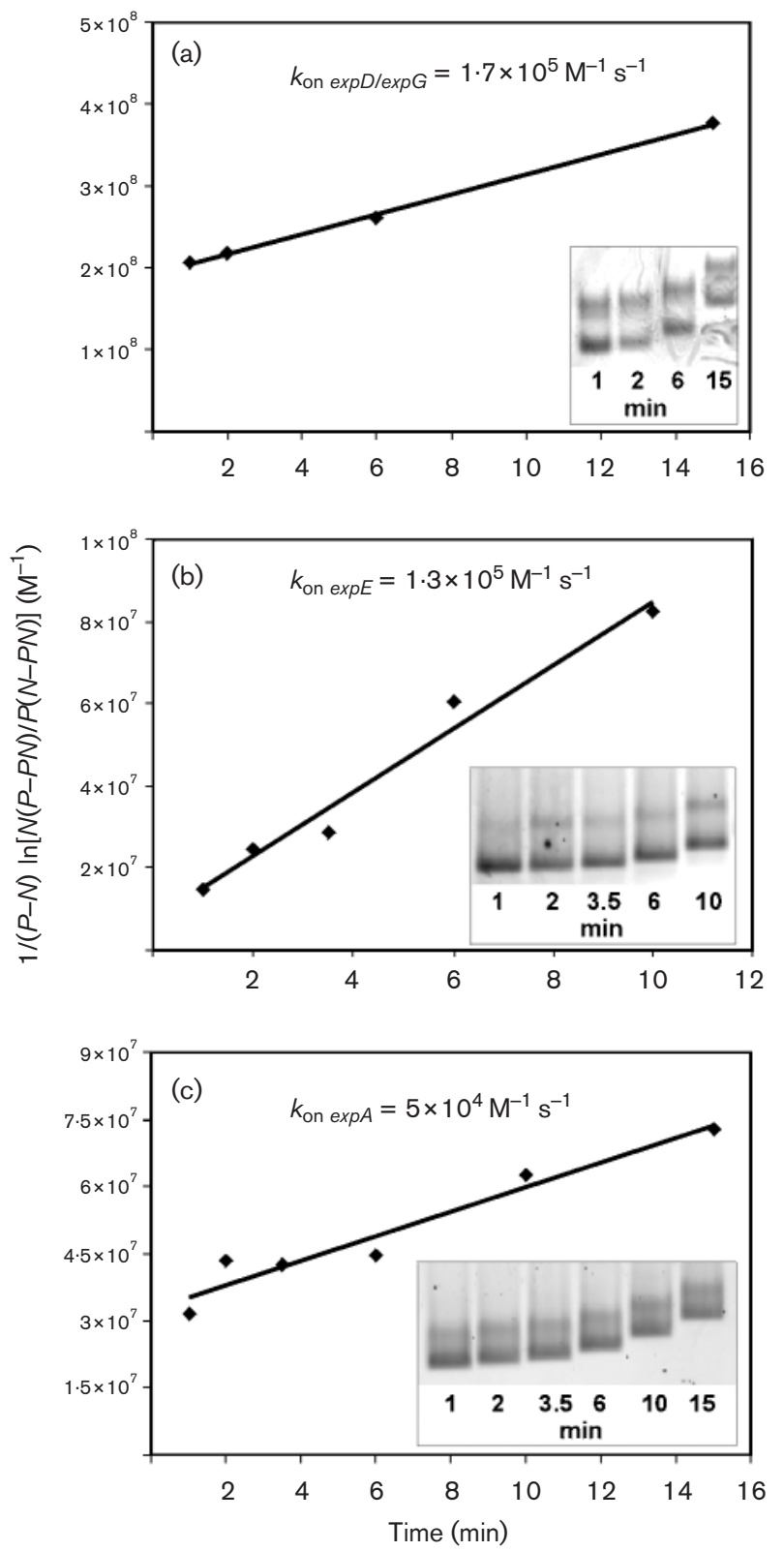

Fig. 7. On-rates $\left(k_{\mathrm{on}}\right)$ of the (a) ExpG-expD/expG, (b) ExpG$\exp E$ and (c) ExpG-expA protein-DNA complexes: association kinetics, represented by a plot of $1 /(P-N) \ln [N(P-P N) /$ $P(N-P N)]$ versus time. The ExpG protein concentration in the assay was calculated to be (a) $2.8 \times 10^{-8} \mathrm{M}$, (b) $4.5 \times 10^{-8} \mathrm{M}$ and (c) $5.6 \times 10^{-8} \mathrm{M}$. DNA was added to give the following final concentrations: (a) $3.64 \times 10^{-8} \mathrm{M}$, (b) $1.6 \times 10^{-8} \mathrm{M}$ and (c) $4.68 \times 10^{-8} \mathrm{M}$. The slope represents $k_{\text {on }}$. The insets show the original data obtained from an EMSA. 
Table 1. On-rates $\left(k_{\text {on }}\right)$, off-rates $\left(k_{\text {off }}\right)$ and dissociation constants $\left(K_{\mathrm{d}}\right)$ of the ExpG(His $)_{6}-\mathrm{DNA}$ complexes

\begin{tabular}{|c|c|c|c|c|c|}
\hline \multirow{2}{*}{$\begin{array}{l}\text { Promoter } \\
\text { region }\end{array}$} & \multicolumn{2}{|c|}{$k_{\mathrm{on}}\left(\mathrm{M}^{-1} \mathrm{~s}^{-1}\right)$} & \multirow[t]{2}{*}{$k_{\text {off }}\left(s^{-1}\right)$} & \multicolumn{2}{|c|}{$K_{\mathrm{d}}(\mathrm{M})$} \\
\hline & Monomer & Dimer & & Monomer & Dimer \\
\hline 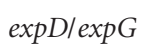 & $1 \cdot 7 \times 10^{5}$ & $3 \cdot 7 \times 10^{5}$ & $4 \cdot 3 \times 10^{-4}$ & $2.5 \times 10^{-9}$ & $1 \cdot 2 \times 10^{-9}$ \\
\hline $\exp E 1$ & $1 \cdot 3 \times 10^{5}$ & $5 \cdot 0 \times 10^{5}$ & $2 \cdot 9 \times 10^{-4}$ & $2 \cdot 2 \times 10^{-9}$ & $5 \cdot 8 \times 10^{-10}$ \\
\hline $\exp A 1$ & $5 \cdot 0 \times 10^{4}$ & $1 \cdot 0 \times 10^{5}$ & $1 \cdot 3 \times 10^{-4}$ & $2 \cdot 6 \times 10^{-9}$ & $1 \cdot 3 \times 10^{-9}$ \\
\hline
\end{tabular}

initiation (Sauer et al., 1982). In repressor proteins the HTH binding motif is predominantly situated at the N-terminus, whereas activators mainly contain this motif at the Cterminus (Perez-Rueda \& Collado-Vides, 2001). This observation is in agreement with the C-terminal position of this motif in the transcriptional activator ExpG.

\section{Binding kinetics of the ExpG-DNA complexes}

With this competition assay available, we aimed to determine the on- and off-rates of the $\operatorname{ExpG(His)}{ }_{6}-\mathrm{DNA}$

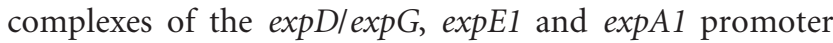
fragments (see Methods). To determine the protein concentration for analysis of the binding kinetics we carried out EMSAs with increasing protein concentrations and DNA fragment II (Fig. 6), DNA fragment I and DNA fragment III (data not shown). Only at a protein concentration of $0 \cdot 28 \mu \mathrm{g} \mathrm{l}^{-1}\left(1 \cdot 2 \times 10^{-5} \mathrm{M}\right)$ was the electrophoretic mobility of the protein-DNA complex more strongly reduced in comparison to the lower protein concentrations. This may indicate the formation of a protein tetramer-DNA complex compared to a protein dimer-DNA complex that is probably formed at lower protein concentrations (Fig. 6). The protein concentration used in the EMSAs to investigate the binding kinetics of ExpG and the different exp promoter fragments was in the range $6 \cdot 5 \times 10^{-4} \mu \mathrm{g} \mu \mathrm{l}^{-1}$ to $0 \cdot 013 \mu \mathrm{g} \mu \mathrm{l}^{-1}\left(2 \cdot 8 \times 10^{-8} \mathrm{M}\right.$ to $5 \cdot 6 \times 10^{-7} \mathrm{M}$ ).

On-rates $\left(k_{\mathrm{on}}\right)$ measured for the binding reaction of

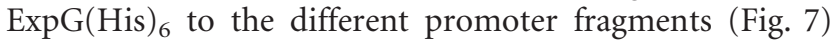
are summarized in Table 1. Since the results of the GPC analysis support the assumption that ExpG binds the DNA as a dimer we also calculated the on-rates for this DNA-dimer protein interaction (Table 1).

The dissociation kinetics of the $\operatorname{ExpG(His)})_{6}$-mediated binding reaction were investigated by using the unlabelled fragments I, II and III (Fig. 2a) as competitors (Fig. 8). This revealed off-rates $\left(k_{\mathrm{off}}\right)$ (Table 1$)$ at the lower limit of the mean off-rate $k_{\text {off }}=(1 \cdot 2 \pm 1 \cdot 0) \times 10^{-3} \mathrm{~s}^{-1}$ for all three DNA target sequences which were previously obtained by AFM force spectroscopy experiments (Bartels et al., 2003). From the on- and off-rates the different dissociation constants $K_{\mathrm{d}}$ were estimated for the complexes between

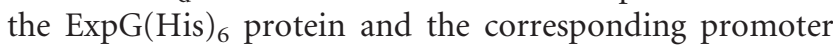
fragments (Table 1). Many other transcriptional regulators, e.g. PcaU, MucR or Lrp, are characterized by quite similar dissociation constants in the nanomolar range (BertramDrogatz et al., 1997; Calvo \& Matthews, 1994; Popp et al., 2002).
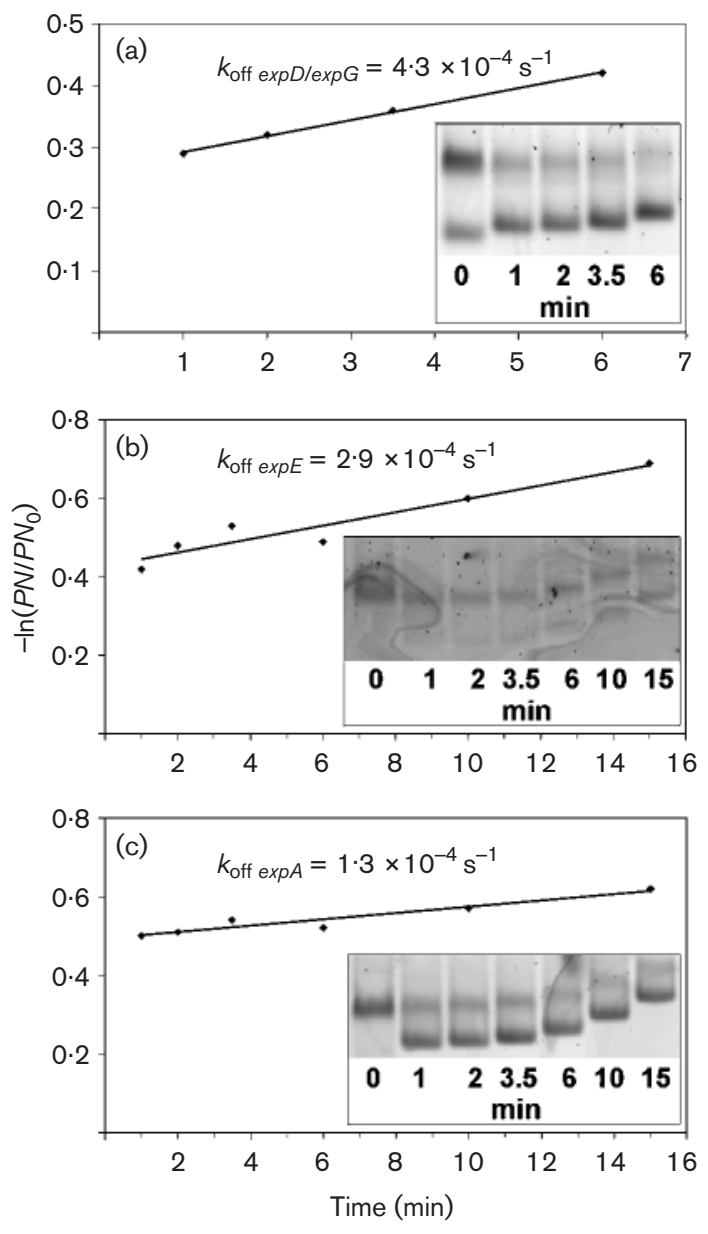

Fig. 8. Off-rates $\left(k_{\text {off }}\right)$ of the (a) ExpG-expD/expG, (b) ExpG$\exp E$ and (c) ExpG-expA protein-DNA complexes: dissociation kinetics, represented by a plot of $-\ln \left(P N / P N_{0}\right)$ versus time. The ExpG protein concentration in the assay was calculated to be (a) $2.8 \times 10^{-7} \mathrm{M}$, (b) and (c) $5.6 \times 10^{-7} \mathrm{M}$. The slope represents $k_{\text {off }}$ DNA was added to give the following final concentrations: (a) $3.64 \times 10^{-8} \mathrm{M}$, (b) $1.06 \times 10^{-7} \mathrm{M}$ and (c) $4.68 \times 10^{-8} \mathrm{M}$. The insets show the original data obtained from an EMSA. The data obtained from the sample taken at 0 min (directly before the addition of competitor) was used to calculate $P N_{0}$. 
We investigated the details of $\operatorname{ExpG}(\mathrm{His})_{6}$ binding by single-molecule AFM force spectroscopy under different retract velocities. By varying the time-dependency of the external forces, i.e. the loading rate (loading rate $=$ retract velocity $\times$ molecule elasticity), natural thermal off-rates can be measured (Bartels et al., 2003; Evans \& Ritchie, 1997; Merkel et al., 1999; Schwesinger et al., 2000; Strunz et al., 1999). Dynamic force spectroscopy (Fig. 9) revealed a distinct difference in the kinetics between the wild-type sequence (KF-Ale) and its two mutated but still binding derivates (KF-Alg and KF-A1h). When the unbinding forces are plotted against the corresponding loading rates on a logarithmic scale, the experimental data can be fitted to a linear function according to the formula given by Strunz et al. (1999):

$F=\frac{k_{\mathrm{B}} T}{x_{\beta}} \ln \frac{x_{\beta} r}{k_{\mathrm{B}} T k_{\mathrm{off}}}$

where $F$ is the most probable unbinding force, $k_{\mathrm{B}} T=$ $4 \cdot 114 \mathrm{pN} \mathrm{nm}$ (at $298 \mathrm{~K}$ ) is a Boltzmann factor, $x_{\beta}$ is the distance between the minimum of the potential well of the bound state and the maximum of the energy barrier separating the bound state from the free state along the reaction coordinate, $r$ is the loading rate, and $k_{\text {off }}$ is the thermal off-rate under zero load. The natural thermal off-rate $k_{\text {off }}$ can be derived by extrapolating the linear fit to the state of zero external force. We measured an off-rate $k_{\text {off }}=(4 \cdot 4 \pm 2 \cdot 5) \times 10^{-4} \mathrm{~s}^{-1}$ for the binding of $\operatorname{ExpG}(\mathrm{His})_{6}$ to the wild-type DNA fragment, but $k_{\text {off }}=$ $(5 \cdot 3 \pm 1 \cdot 5) \times 10^{-3} \mathrm{~s}^{-1}$ for fragment KF-A1h with a mutation in box 2 and even $k_{\text {off }}=(1 \cdot 3 \pm 0 \cdot 2) \times 10^{-2} \mathrm{~s}^{-1}$ for fragment KFA1g with a mutation in box 1 . Thus, mutations in the box 1 and box 2 regions resulted in DNA

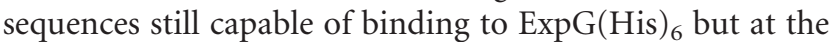
expense of a higher off-rate (i.e. a lower lifetime of the bond). We reason that the motifs box 1 and box 2 complement the $21 \mathrm{bp}$ core region by fulfilling an important structural function in the binding of the $\operatorname{ExpG(His)_{6}}$ protein, namely to stabilize the protein-DNA complex.

\section{Conclusions}

Our experiments demonstrate that the palindromic sequence within the $\exp A$ promoter region is essential for binding of $\operatorname{ExpG}(\mathrm{His})_{6}$ and suggest that the flanking sequence elements box 1 and box 2 contribute significantly to an efficient DNA-protein interaction. These findings were not only confirmed by standard ensemble methods, but also supported by data from AFM single-molecule force spectroscopy. AFM imaging explored the topography of the binding site in buffer solution conditions and suggests a change in DNA conformation upon binding of $\operatorname{ExpG}(\mathrm{His})_{6}$. The dissociation constants $K_{\mathrm{d}}$ determined for the complex of $\operatorname{ExpG}(\mathrm{His})_{6}$ and the corresponding promoter fragments are in good agreement with $K_{\mathrm{d}}$ values of other transcriptional regulators. The $k_{\text {off }}$ rates obtained by the EMSA competition assay are at the lower limit of the mean off-rate for the $\exp A 1, \exp D / \exp G$ and $\exp E 1$ promoter

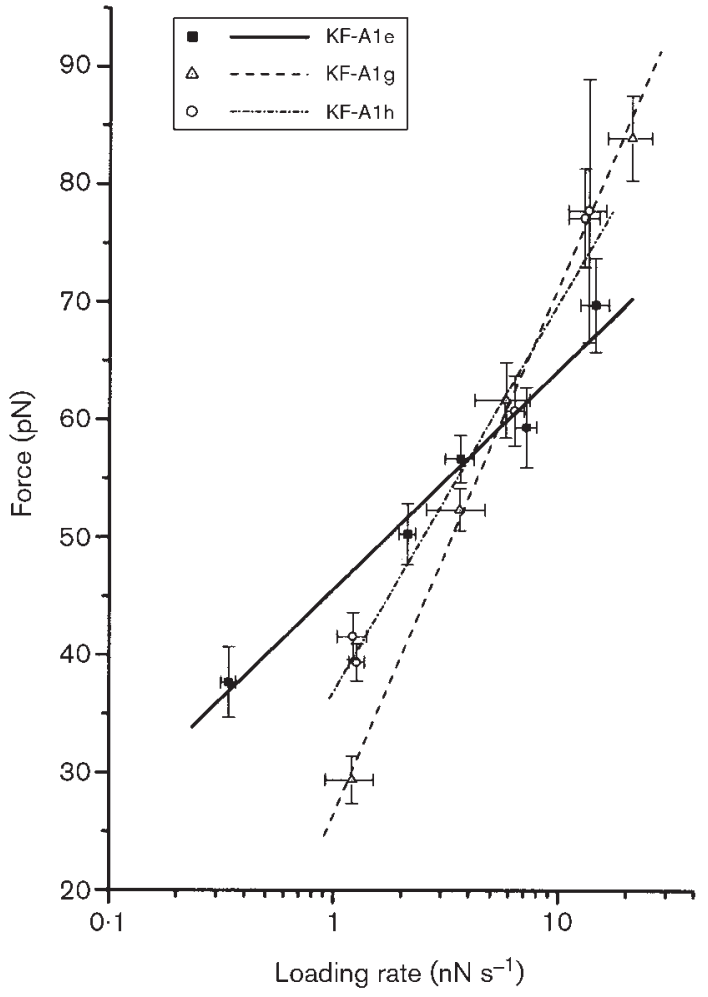

Fig. 9. Dynamic force spectroscopy. Loading rate dependent measurements (loading rate $=$ retract velocity $\times$ molecule elasticity) are displayed for complexes formed by the ExpG(His) protein and three DNA fragments: the wild-type sequence (KF$\mathrm{A} 1 \mathrm{e})$ and mutant fragments with nucleotide changes in box 1 (KF-A1g) and box 2 (KF-A1h). The most probable unbinding force increases with the natural logarithm of the loading rate (Evans \& Ritchie, 1997). By extrapolating the linear fit to the state of zero external force, the natural thermal off-rate can be derived (Strunz et al., 1999). The off-rates differ by more than an order of magnitude, with $k_{\text {off }}(\mathrm{KF}-\mathrm{A} 1 \mathrm{e})=(4 \cdot 4 \pm 2 \cdot 5) \times 10^{-4} \mathrm{~s}^{-1}$, $k_{\text {off }}(\mathrm{KF}-\mathrm{A} 1 \mathrm{~h})=(5 \cdot 3 \pm 1 \cdot 5) \times 10^{-3} \mathrm{~s}^{-1}$ and $k_{\text {off }}(\mathrm{KF}-\mathrm{A} 1 \mathrm{~g})=(1 \cdot 3 \pm$ $0 \cdot 2) \times 10^{-2} \mathrm{~s}^{-1}$.

regions previously measured by AFM force spectroscopy using a $\mathrm{N}$-terminal (His) ${ }_{6}$ ExpG fusion protein (Bartels et al., 2003). This makes it unlikely that the DNA-binding activity was severely affected in the same way by both tags. Furthermore, dynamic force spectroscopy reveals a distinct difference in the kinetics of the wild-type binding sequence and the fragments containing mutations within the box 1 and box 2 motifs. Whereas the EMSA experiments detected binding or non-binding of the DNA-protein complex, the analysis at single molecule level showed that the mutated sequences of box 1 and box 2 lead to a higher off-rate. The $\operatorname{ExpG(His)}{ }_{6}$ binding sites characterized in this study overlap with the putative PHO boxes previously predicted in the exp promoter regions (Rüberg et al., 1999), suggesting an interference of PhoB and ExpG binding in the regulation of exp promoter activities. 


\section{ACKNOWLEDGEMENTS}

We thank A. Pühler for helpful discussion. This work was supported by SFB 613 from the Deutsche Forschungsgemeinschaft.

\section{REFERENCES}

Alekshun, M. N. \& Levy, S. B. (1999). The mar regulon: multiple resistance to antibiotics and other toxic chemicals. Trends Microbiol 7, 410-413.

Astete, S. G. \& Leigh, J. A. (1996). mucS, a gene involved in activation of galactoglucan (EPS II) synthesis gene expression in Rhizobium meliloti. Mol Plant-Microbe Interact 9, 395-400.

Bartels, F. W., Baumgarth, B., Anselmetti, D., Ros, R. \& Becker, A. (2003). Specific binding of the regulatory protein ExpG to promoter regions of the galactoglucan biosynthesis gene cluster of Sinorhizobium meliloti - a combined molecular biology and force spectroscopy investigation. J Struct Biol 143, 145-152.

Becker, A., Rüberg, S., Küster, H., Roxlau, A. A., Keller, M., Ivashina, T., Cheng, H. P., Walker, G. C. \& Pühler, A. (1997). The 32-kilobase exp gene cluster of Rhizobium meliloti directing the biosynthesis of galactoglucan: genetic organization and properties of the encoded gene products. J Bacteriol 179, 1375-1384.

Bertram-Drogatz, P. A., Rüberg, S., Becker, A. \& Pühler, A. (1997). The regulatory protein MucR binds to a short DNA region located upstream of the mucR coding region in Rhizobium meliloti. Mol Gen Genet 254, 529-538.

Bertram-Drogatz, P. A., Quester, l., Becker, A. \& Pühler, A. (1998). The Sinorhizobium meliloti MucR protein, which is essential for the production of high-molecular-weight succinoglycan exopolysaccharide, binds to short DNA regions upstream of exoH and exoY. Mol Gen Genet 257, 433-441.

Bisswanger, H. (1994). Enzymkinetik: Theorie und Methoden. Weinheim: $\mathrm{VCH}$.

Bradford, M. M. (1976). A rapid and sensitive method for the quantitation of microgram quantities of protein utilizing the principle of protein-dye binding. Anal Biochem 72, 248-254.

Calvo, J. M. \& Matthews, R. G. (1994). The leucine-responsive regulatory protein, a global regulator of metabolism in Escherichia coli. Microbiol Rev 58, 466-490.

Casse, F., Boucher, C., Hulliot, J. S., Michel, M. \& Dénarié, F. (1979). Identification and characterization of large plasmids in Rhizobium meliloti using agarose gel electrophoresis. J Bacteriol 113, 229-242.

Cohen, S. P., Hachler, H. \& Levy, S. B. (1993). Genetic and functional analysis of the multiple antibiotic resistance (mar) locus in Escherichia coli. J Bacteriol 175, 1484-1492.

Egland, P. G. \& Harwood, C. S. (1999). BadR, a new MarR family member, regulates anaerobic benzoate degradation by Rhodopseudomonas palustris in concert with AadR, an Fnr family member. J Bacteriol 181, 2102-2109.

Evans, E. \& Ritchie, K. (1997). Dynamic strength of molecular adhesion bonds. Biophys J 72, 1541-1555.

Fried, M. \& Crothers, D. M. (1981). Equilibria and kinetics of lac repressor-operator interactions by polyacrylamide gel electrophoresis. Nucleic Acids Res 9, 6505-6525.

Glazebrook, J. \& Walker, G. C. (1989). A novel exopolysaccharide can function in place of the calcofluor-binding exopolysaccharide in nodulation of alfalfa by Rhizobium meliloti. Cell 56, 661-672.

Gonzalez, J. E., Reuhs, B. L. \& Walker, G. C. (1996). Low molecular weight EPS II of Rhizobium meliloti allows nodule invasion in Medicago sativa. Proc Natl Acad Sci U S A 93, 8636-8641.
Hansma, H. G. \& Laney, D. E. (1996). DNA binding to mica correlates with cationic radius: assay by atomic force microscopy. Biophys J 70, 1933-1939.

Henikoff, S., Haughn, G. W., Calvo, J. M. \& Wallace, J. C. (1988). A large family of bacterial activator proteins. Proc Natl Acad Sci U S A 85, 6602-6606.

Her, G. R., Glazebrook, J., Walker, G. C. \& Reinhold, V. N. (1990). Structural studies of a novel exopolysaccharide produced by a mutant of Rhizobium meliloti strain Rm1021. Carbohydr Res 198, 305-312.

Hutter, J. L. \& Bechhoefer, J. (1993). Calibration of atomic-force microscope tips. Rev Sci Instrum 7, 1868-1873.

Keller, M., Roxlau, A., Weng, W. M., Schmidt, M., Quandt, J., Niehaus, K., Jording, D., Arnold, W. \& Pühler, A. (1995). Molecular analysis of the Rhizobium meliloti mucR gene regulating the biosynthesis of the exopolysaccharides succinoglycan and galactoglucan. Mol Plant-Microbe Interact 8, 267-277.

Komeda, H., Kobayashi, M. \& Shimizu, S. (1996). Characterization of the gene cluster of high-molecular-mass nitrile hydratase (HNHase) induced by its reaction product in Rhodococcus rhodochrous J1. Proc Natl Acad Sci U S A 93, 4267-4272.

Lane, D., Prentki, P. \& Chandler, M. (1992). Use of gel retardation to analyze protein-nucleic acid interactions. Microbiol Rev 56, 509-528.

Lloret, J., Martin, M., Oruezabal, R. I., Bonilla, I. \& Rivilla, R. (2002). MucR and mucS activate exp genes transcription and galactoglucan production in Sinorhizobium meliloti EFB1. Mol Plant-Microbe Interact 15, 54-59.

Long, S. R. (2001). Genes and signals in the Rhizobium-legume symbiosis. Plant Physiol 125, 69-72.

Lysetska, M., Knoll, A., Boehringer, D., Hey, T., Krauss, G. \& Krausch, G. (2002). UV light-damaged DNA and its interaction with human replication protein A: an atomic force microscopy study. Nucleic Acids Res 30, 2686-2691.

Lyubchenko, Y., Shlyakhtenko, L., Harrington, R., Oden, P. \& Lindsay, S. (1993). Atomic force microscopy of long DNA: imaging in air and under water. Proc Natl Acad Sci U S A 90, 2137-2140.

Merkel, R., Nassoy, P., Leung, A., Ritchie, K. \& Evans, E. (1999). Energy landscapes of receptor-ligand bonds explored with dynamic force spectroscopy. Nature 397, 50-53.

Miller, P. F. \& Sulavik, M. C. (1996). Overlaps and parallels in the regulation of intrinsic multiple-antibiotic resistance in Escherichia coli. Mol Microbiol 21, 441-448.

Oke, V. \& Long, S. R. (1999). Bacteroid formation in the Rhizobiumlegume symbiosis. Curr Opin Microbiol 2, 641-646.

Oscarsson, J., Mizunoe, Y., Uhlin, B. E. \& Haydon, D. J. (1996). Induction of haemolytic activity in Escherichia coli by the slyA gene product. Mol Microbiol 20, 191-199.

Pellock, B. J., Teplitski, M., Boinay, R. P., Bauer, W. D. \& Walker, G. C. (2002). A LuxR homolog controls production of symbiotically active extracellular polysaccharide II by Sinorhizobium meliloti. $J$ Bacteriol 184, 5067-5076.

Perez-Rueda, E. \& Collado-Vides, J. (2001). Common history at the origin of the position-function correlation in transcriptional regulators in archaea and bacteria. J Mol Evol 53, 172-179.

Popp, R., Kohl, T., Patz, P., Trautwein, G. \& Gerischer, U. (2002). Differential DNA binding of transcriptional regulator PcaU from Acinetobacter sp. strain ADP1. J Bacteriol 184, 1988-1997.

Rüberg, S., Pühler, A. \& Becker, A. (1999). Biosynthesis of the exopolysaccharide galactoglucan in Sinorhizobium meliloti is subject to a complex control by the phosphate-dependent regulator PhoB and the proteins ExpG and MucR. Microbiology 145, 603-611. 
Sauer, R. T., Yocum, R. R., Doolittle, R. F., Lewis, M. \& Pabo, C. O. (1982). Homology among DNA-binding proteins suggests use of a conserved super-secondary structure. Nature 298, 447-451.

Schell, M. A. (1993). Molecular biology of the LysR family of transcriptional regulators. Annu Rev Microbiol 47, 597-626.

Schwesinger, F., Ros, R., Strunz, T., Anselmetti, D., Guntherodt, H. J., Honegger, A., Jermutus, L., Tiefenauer, L. \& Pluckthun, A. (2000). Unbinding forces of single antibody-antigen complexes correlate with their thermal dissociation rates. Proc Natl Acad Sci U S A 97, 9972-9977.

Spaink, H. P. (2000). Root nodulation and infection factors produced by rhizobial bacteria. Annu Rev Microbiol 54, 257-288.

Strunz, T., Oroszlan, K., Schafer, R. \& Guntherodt, H. J. (1999). Dynamic force spectroscopy of single DNA molecules. Proc Natl Acad Sci U S A 96, 11277-11282.

Sulavik, M. C., Gambino, L. F. \& Miller, P. F. (1995). The MarR repressor of the multiple antibiotic resistance (mar) operon in Escherichia coli: prototypic member of a family of bacterial regulatory proteins involved in sensing phenolic compounds. $\mathrm{Mol}$ Med 1, 436-446.

Wang, L. X., Wang, Y., Pellock, B. \& Walker, G. C. (1999). Structural characterization of the symbiotically important lowmolecular-weight succinoglycan of Sinorhizobium meliloti. J Bacteriol 181, 6788-6796.

Yanisch-Perron, C., Vieira, J. \& Messing, J. (1985). Improved M13 phage cloning vectors and host strains: nucleotide sequences of the M13mp18 and pUC19 vectors. Gene 33, 103-119.

Young, R. A. \& Davis, R. W. (1983). Yeast RNA polymerase II genes: isolation with antibody probes. Science 222, 778-782.

Zhan, H. J., Levery, S. B., Lee, C. C. \& Leigh, J. A. (1989). A second exopolysaccharide of Rhizobium meliloti strain SU47 that can function in root nodule invasion. Proc Natl Acad Sci U S A 86, 3055-3059.

Zhan, H. J., Lee, C. C. \& Leigh, J. A. (1991). Induction of the second exopolysaccharide (EPSb) in Rhizobium meliloti SU47 by low phosphate concentrations. J Bacteriol 173, 7391-7394. 